\title{
RITMO E EXPRESSIVIDADE DO DÍSTICO ELEGÍACO: TIBULO 1.3.1-4
}

\author{
João Batista Toledo Prado*
}

Universidade Estadual Paulista

Resumo. A partir da consciência de que sílabas longas e breves (cor)respondem-se mutuamente num sistema de oposições básicas, é imprescindível verificar o papel desempenhado por elas nas cadeias fonossintáticas que formam os pés métricos, função que elas só desempenham através de valores psicológicos investidos nas estruturas hieraquicamente organizadas do verso, geradas a partir da oposição básica que elas encetaram. Tais valores são as propriedades combinatórias que os segmentos do nível seguinte permitem, quais sejam os metros e, em seguida, os pés métricos que eles realizam ou integram, daí o verso e, eventualmente, a estrofe, de modo a estruturar o poema todo. Tendo em vista que se trata sempre de concatenação de elementos, o conjunto formado tenderá a gerar uma orientação, isto é, um sentido, que é a princípio um determinado ritmo poético. O ritmo, entretanto, é influenciado por outras ocorrências ao longo da cadeia fonossintática, como as cesuras que incidem sobre a linha do verso. A partir da passagem de Tibulo, 1.3.1-4, o presente texto propõe levar em conta tais fatores para analisar o andamento rítmico-melódico da unidade estrófica formada pelo dístico elegíaco, com especial enfoque nas possibilidades de escansão geradas pela cesura-diérese fixa do pentâmetro e suas consequências para a expressividade poética.

Palavras-chave. Ritmo poético; dístico elegíaco; escansão; Tibulo; semiologia; expressividade. D.O.I. 10.11606/issn.2358-3150.v19i2p114-129

Et Maro dat tales [priapeos]; sed quia distinctio verba dissociat nectitve aliter nec partibus aequis distingui patitur pedes, effugit sonus aurem ${ }^{1}$ (Terentianus Maurus, De Metris, vv. 2769-71)

* Doutor em Letras Clássicas pela Universidade de São Paulo (1997). Professor da Área de Latim do Departamento de Linguística da Faculdade de Ciências e Letras da UNESP, Câmpus de Araraquara. O autor deseja agradecer à Fundação de Amparo à Pesquisa do Estado de São Paulo pela concessão de uma bolsa de estudos que lhe permitiu desenvolver uma investigação de pós-doutoramento da qual este texto é um dos resultados (FAPESP, processo n 2015/02415-9).

* Artigo recebido em 12.abr.2016 e aceito para publicação em 04.jul.2016. Uma versão reduzida deste texto foi apresentada como conferência no Colóquio Internacional Voix, geste et rythme dans la poésie ancienne et moderne, que teve lugar entre 15 e 17 de outubro de 2015 na Maison de la Recherche da Université de Rouen (França).

1 "Virgílio também compõe nesses versos [priapeus], mas porque a divisão [em pés] separa / ou une as palavras de uma maneira diferente, e não permite que os pés / sejam separados em partes iguais, o som engana os ouvidos" (todas as traduções de línguas estrangeiras para o vernáculo português são de responsabilidade do autor, a menos que se indique o contrário). 
Apesar de AbORdAR questões de MÉTRICA ClÁsSICA latina, É PRUdENTE advertir de saída que o ponto de vista adotado neste texto não é, ao menos em sentido estrito, aquele que costumeiramente orienta a perspectiva de um metricista, de hábito sempre interessado em fenômenos de identificação, taxonomia e classificação sistemática do mais numeroso conjunto de metros, pés, versos, bem como na infinidade de combinações possíveis entre eles, procedimentos e preocupações que podem ser vistos nas obras de todos os gramáticos antigos que se ocuparam dos estudos de métrica, hoje chamados metricologistas ou artígrafos. Dessa forma, o ponto de vista em que se baseia este texto é o de quem está mais interessado no(s) processo(s) que a poesia utiliza para criar vários dos sentidos poéticos percebidos no poema, ou seja, o processo pelo qual certos fenômenos, percebidos primeiramente no nível da expressão de um poema (mas sempre articulados e orientados pelo nível do conteúdo) pode levar a uma reinterpretação de seu(s) sentido(s). Esse ponto de vista poderia ser chamado uma semiologia de expressividade, abordagem que se ocupa com reconhecer os mecanismos de significação pelos quais a poesia torna poético um um texto, qualquer que venha a ser sua matéria.

Essa posição coloca já de saída um problema para o estudo da poesia clássica grega e latina, porque a investigação dos processos expressivos, que levam a reinterpretar o sentido de poemas, a despeito de depender da inter-relação entre conteúdo e expressão, tem geralmente início na superfície textual, mais exatamente no plano da expressão, em que ocorrem vários acidentes de natureza fonética e fonológica que, não raro, sinalizam momentos de privilegiada expressividade poética. A fortuna histórica do grego e do latim foi tal que se podem estudar hoje praticamente todos os níveis dessas línguas antigas, sejam eles morfossintáticos, semânticos, textuais ou discursivos, exceção feita, porém, à dimensão fonética, irremediavelmente perdida junto com o desaparecimento do mítico "último falante" do grego antigo e do latim. Esbarra-se, assim, na perda histórica dos dados fonéticos, cujo conhecimento pleno e controle seguro só podem dar-se por meio de testemunho empírico, tornado impossível diante do desaparecimento completo de todas as comunidades falantes do grego antigo e do latim.

Apesar da perda inelutável do dado empiricamente verificável, isto é, do dado fonético, impõe-se o conhecido primado linguístico segundo o qual, em matéria de linguagem, fatos de fala precedem sempre ${ }^{2}$ (Saussure 1995, 37). No âmbito das investigações da expressividade poética, o postu-

\footnotetext{
${ }^{2}$ Cf.: "Sans doute, ces deux objets sont étroitement liés et se supposent l'un l'autre: la langue est nécessaire pour que la parole soit intelligible et produise tous ses effets; mais celle-ci est nécessaire pour que la langue s'établisse; historiquement, le fait de parole précède toujours." (Saussure 1995, 37).
} 
lado de que não há língua sem fala e, portanto, nem fala sem língua ${ }^{3}$ (Saussure 1995, 112) implicará a dimensão fônica da linguagem, qualquer que seja o estado histórico da língua sob exame. Por isso, é preciso encontrar mecanismos que superem essa espécie de restrição imposta pelo curso da história, se se pretende chegar a uma investigação da expressividade poética do grego e do latim.

A despeito da incerteza histórica da dimensão fonética de línguas antigas que não deixaram registro seguro de sua oralidade, como são o grego antigo e o latim, essas línguas contam com abundantes testemunhos escritos, diretos e indiretos, que permitem tecer hipóteses de reconstrução de um sistema de oposições básicas. Trata-se aqui, então, não apenas das sugestivas, úteis e instigantes hipóteses como a de Daitz (1984), que fundamentam as mais bem sucedidas experiências de reconstrução do grego e do latim, mas sobretudo dos valores contrastivos que emergem da reconstrução de seu sistema fonológico, como o da oposição de base formada pelo par brevidade ( $~$ ) versus longura $(-)$, responsável por estruturar todo o edifício da poética desses idiomas (metros, pés, versos, estrofes). A abordagem fonológica tem-se provado particularmente útil para explicar fenômenos da ordem da linguagem poética, como já sinalizava Jakobson (1962). ${ }^{4}$

A partir da consciência de que longas e breves (cor)respondem-se mutuamente num sistema de oposições básicas, torna-se importante verificar o papel desempenhado por elas nas cadeias fonossintáticas que formam os pés métricos de um verso, de modo a dialogar, reforçar, refutar e polemizar com o significado dos itens do léxico por meio dos quais elas são expressas. Naturalmente, elas não o fazem por si mesmas, mas através de valores investidos nas estruturas hieraquicamente organizadas, geradas a partir da oposição básica que elas encetaram. Tais valores são as propriedades combinatórias que os segmentos do nível seguinte permitem, quais sejam os metros e, em seguida, os pés métricos que eles realizam ou integram, daí o verso e, eventualmente, a estrofe, de modo a estruturar o poema todo.

Daí, então, tratar-se-á sempre de concatenação de elementos, de forma que o conjunto formado tenderá a gerar uma orientação, isto é, um sentido, que é a princípio um determinado ritmo poético. O ritmo, entre-

Cf.: "[...] il faut une masse parlant pour qu'il y ait une langue. A aucun moment, et contrairement à l'apparence, celle-ci n'existe en dehors du fait social, parce qu'elle est un phénomène sémiologique. Sa nature sociale est un de ces caractères internes; sa définition complète nous place devant deux choses inséparables, [...]" (Saussure 1995, 112).

${ }^{4}$ As posições de Jakobson a esse respeito podem ser lidas na redação do verbete fonema $e$ fonologia, publicada no segundo volume suplementar de uma enciclopédia tcheca sobre a linguagem: "The phonological approach has proven to be particularly fruitful in respect to poetic language, standard language or writing, whereas a complete failure marked the attempts o folder linguistics to treat these domains" (Jakobson 1962, 232). 
tanto, é marcado e influenciado por outras ocorrências ao longo da cadeia fonossintática, como as cesuras que incidem sobre a linha do verso. Tendo em vista que as cesuras do verso intervêm sobre o andamento da frase poética, tal fenômeno também terá a propriedade de (re)orientar, quando não de criar, determinados sentidos.

A cesura, por exemplo, é uma ocorrência que influencia a fonossintaxe do verso e, como tal, deve ser levada em conta nas análises preocupadas com a construção da expressividade. Embora o termo caesura seja derivado do verbo caedere e seja um equivalente do grego touń que, por sua vez, deriva de $\tau \dot{\mu} \mu v o$ - tanto o grego como o latino são verbos do campo semântico de "cortar, seccionar"5 - não há necessidade de entendê-la como corte nem sequer pausa, ao menos não de forma mecânica, já que leituras e declamações de versos nunca parecem requerer pausas físicas que interrompam a sequência da cadeia fonossintática da frase em verso, mesmo em se tratando de poesia composta em latim ou em grego antigo.

A cesura deve ser, então, compreendida antes como um momento de relevo particular no verso, que se dá pela acumulação de duas funções, uma rítmica e outra estilística. Embora possa, por vezes, coincidir com alguma pausa exigida pela sintaxe-semântica da frase, trata-se muito mais de um "lugar rítmico particularmente proeminente, um ponto de referência para o ouvido que tenta captar o fluxo dos metros realizado pelas palavras" ${ }^{\prime \prime}$ (Perini 1982, 222). Conceber e validar cesuras como um ponto de especial relevo no ritmo do poema pode trazer consequências interessantes para a análise da expressividade poética - que leva em conta também vários outros elementos que atuam na composição do poema - como se procurará demonstrar a seguir.

Segue-se agora uma pequena análise dos elementos que atuam para promover a expressividade poética dos dísticos iniciais da Elegia 1.3 de Tibulo. Nessa elegia, endereçada ao patrono literário do poeta, o general Marcus Valerius Messalla Corvinus, o eu-poético descreve-se adoentado e impedido de acompanhar seu patrono numa campanha militar em algum lugar do Mar Egeu. Se, por um lado, o poema presta-se a fazer referência à participação de Messala como general de Octavianus na batalha de Actium, por outro lado, o poema é também uma meditação sobre a morte, que comparece antromorfizada no poema.

Assim, o poema 1.3 principia por um lamento dirigido a Messala, para caracterizar o eu-poético retido por uma enfermidade na ilha estran-

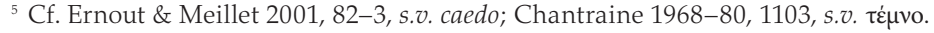

${ }^{6}$ Cf.: "un luogo ritmico di particolare spicco, un punto di riferimento per l'orecchio intento a cogliere il flusso dei metri realizzato dalle parole".
} 
geira de Feácia, onde uma vez já tinha estado o lendário Ulisses ${ }^{7}$ (cf. Odisseia 6.187-210 et 7.37-45). ${ }^{8}$ Em razão disso, o narrador declara que não poderá acompanhar seu patrono "pelas águas do Mar Egeu" (v. 1). Essa estada forçada do eu-poético tibuliano na Feácia foi interpretada por Mills (1974, p. 226 ss.) como uma morte para o narrador, porque ele se vê separado de Messala, de sua vida ideal no campo e, sobretudo, de sua Délia, e propõe, para comprová-lo, que a personificação da ilha (Me tenet /.../ Phaeacia, v. 3) pode ser posta em paralelo com a personificação da própria morte (v. $4^{-5}$ ). $\mathrm{Na}$ sequência do poema, o eu-poético evoca as imagens de sua mãe, irmã ausentes e também de Délia, de forma que, se vier a morrer, não haveria quem lhe prestasse convenientemente as homenagens funerárias (v. 5-10) (vários elementos fúnebres dessa passagem podem ser contrastados com Catulo 68). ' Segue-se uma descrição de sua partida de Roma e de como Délia consultou as sortes para saber se o amado voltaria a salvo (v. 11-22). Por estar doente, ele ironiza a crença de Délia em Ísis, opinando que de nada adiantou ela tê-lo purificado em seu nome, mas ainda assim pede à deusa que o cure, em nome da fé e do culto prestados pela amada à deusa (v. 23-32); acrescenta que ele mesmo dirigir-se-á aos deuses romanos e a seus penates em prol de seu restabelecimento (v. 33-4). Sobrevêm alguns tópoi elegíacos, como a recusatio da guerra, o louvor da vida campestre, a condenação da ambição, em que o eu-poético repudia a guerra e seus perigos, enaltecendo a vida simples de outrora, quando a ganância não havia ainda compelido os homens a uma vida de saques e perigos (v. 33-56). E acrescenta que, se morrer vitima da doença, Amor e Vênus o conduzirão aos Campos Elíseos, descritos pelo narrador como um lugar de perfeição e alegria plenas, repleto de danças, cantos e de amantes que se entregam abertamente ao amor (v. 57-66). A descrição dos Campos Elíseos é seguida pela do Tártaro (v. 67-8o), que, segundo Campbell (1973, p. 155 ss.), é o reverso do paraíso, a segunda e necessária metade do contraste que o narrador estabelece entre o amante e o homem de negotium e militia. Por fim, o poema se encerra com o desejo de volta a Roma e do reencontro com sua amada Délia, numa cena cuja descrição serena lembra a lenda da casta Lucrécia (cf. Tito Lívio 1.57), ${ }^{10}$ exceto porque, em todos os outros poemas, Délia é retratada como uma anti-Lucrécia, permissiva, volúvel e nada casta, o que leva o narrador a esta-

Feácia e Córcira, comenta Ponchont (1950: 24, n.1), eram os antigos nomes da ilha de Corfu. Ulisses naufragou nessa ilha e, por isso, Tibulo identifica seu desterro com o do general grego (cf. Bright 1971, 197-214).

${ }^{8}$ Cf. Homer 1945, 220-1 et 234-5 respectivamente.

${ }^{9}$ Cf. Catullus 2005, 172-9.

${ }^{10}$ Cf. Livy 1957, 196-201. 
belecer, a seu critério, um modelo idealizado, que corresponde ao protótipo de virtude romano para a mulher (v. 81-94).

Tal é o contexto da elegia, de onde se sacam os dois primeiros dísticos para serem examinados à luz dos procedimentos que constroem sua expressividade poética. Quando procede à escansão dos dois dísticos iniciais, a representação gráfica do plano prosódico pode ser assim representado:

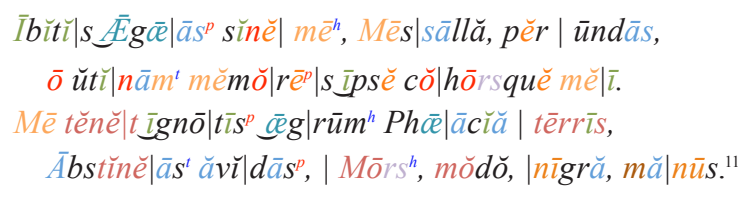

(Tibulo 1.3.1-4)

Irás sem mim, Messala, ao Mar Egeu,

ó!, oxalá lembrados,

tu, tua tropa de mim.

Retém-me enfermo a Feácia, terra estranha:

retires, negra Morte,

ah!, tuas ávidas mãos. ${ }^{12}$

Nos hexâmetros e pentâmetros da passagem transcrita, foram assinalados e discriminados os pés datílicos e espondaicos, bem como os empréstimos fonológicos das consoantes finais às palavras seguintes que iniciam por vogais (os sândis) e as sinalefas. Foram também assinaladas as cesuras $(\mathrm{t}=$ tritemímera; $\mathrm{p}=$ pentemímera; $\mathrm{h}$ = heftemímera). Em vermelho foram indicadas as cesuras principais e reais, isto é, aquelas ativas e com função indiscutível no verso; em azul, aparecem as cesuras secundárias e potenciais, que, embora não sejam ativas, desempenham um papel coad-

\footnotetext{
${ }^{11}$ Além dos tradicionais diacríticos para marcar longas e breves e das divisões em pés métricos com barras verticais, a escansão dos dísticos também empregou outras formas de notação: (a) cores variadas que visam a colocar em relevo recorrências e paralelismos - nunca acidentais - do material fônico (assonâncias, aliterações, dispersão e concentração de fonemas, etc.); (b) alças subscritas para marcar os sândis fonossintáticos (empréstimos da consoante final de uma palavra à vogal inicial da palavra seguinte); (c) três letras sobrescritas ( $\mathrm{p}=$ pentemímera; $\mathrm{t}=$ tritemímera; $\mathbf{h}=$ heftemímera) para assinalar as cesuras principais (em vermelho) e secundárias (em azul).

${ }^{12}$ Uma versão francesa em versos rítmicos poderia ser: "Vous irez, Messalla, mais sans moi sur les eaux de la mer du Égée: / souveniez, je souhaite, vos troupes et vous même de moi: / Phéacie tout malade m'arrête, à travers des cettes terres étrangères / mais toi même, o noire Mort, éloigniez vos deux mains désireuses". Esse exercício de tradução foi diretamente inspirado num processo tradutório capaz "de trouver un hexamètre qui 'marche" na língua de Valéry, como se pode constatar na comparação com versos como "Chante, déesse, l'ire du Péléide Achille / ire maudite, qui fit la douleur de la foule achéenne..." (Brunet 2010, 36).
} 
jutório, em colaboração com as cesuras principais, para destacar palavras e segmentos-chave. Assinalar cesuras potenciais é uma consequência do princípio regulador e definidor das cesuras, que, ao menos potencialmente, existem toda vez em que uma palavra corta o pé em duas metades. Quando se leva em conta que as cesuras não são pausas físicas, mas relevos psicológicos na topografia do verso, percebe-se que também as potenciais podem atuar em conjunção com a(s) cesura(s) principal(is) e ativa(s), a fim de sublinhar determinados segmentos, o que cria outras possibilidades de leitura.

Embora cesuras desempenhem um importante papel na produção de sentidos conotados no verso, elas atuam em conjunção com o esquema geral de distribuição de pés no verso, bem como com outros elementos do plano da expressão, tais como assonâncias, aliterações, vários graus de procedimentos paronomásticos, paralelismos sintagmáticos como os quiasmos, distribuição mais ou menos regular de fonemas etc., de sorte que tudo colaborará para o processo de significação da máquina verbal do poema.

Sendo assim, no hexâmetro 1.3.1 observa-se tanto que o plano do conteúdo faz referência topológica às águas do mar Egeu, como que uma alternância perfeitamente regular entre dátilos (pés 1, 3 e 5) e espondeus (pés 2, 4 e 6) constrói o verso de modo a recriar o movimento rítmico das marés. A cesura pentemímera, em conjunto com a sugestão de uma cesura heftemímera, destaca o sintagma adverbial sine me ("sem mim"), conferindo relevo à ideia central do início do poema, que é o abandono das responsabilidades militares do eu-poético, incapacitado de acompanhar seu patrono na campanha militar da Batalha de Actium. Além disso, o primeiro hemistíquio produz um forte contraste vocálico entre a vogal alta e fechada /i/ no $1^{\circ}$ pé e a vogal baixa e aberta /a/, que ocorre tanto em -as como no ditongo - ae. Esse contraste é ainda reforçado pela concentração da vogal alta em pés distintos: vogal alta e fechada no $1^{\circ}$ pé em contraste com as vogais abertas no $2^{\circ}$. Embora de modo menos radical e evidente, registra-se também um contraste entre vogais altas $(/ \mathrm{i} / \mathrm{e} / \mathrm{u} /)$, média (/e/) e baixa $(/ \mathrm{a} /)$ em todos os demais pés do verso, colaborando com a representação icônica da oscilação das marés e fornecendo, quem sabe, também uma sugestão de rumorejo. O sândi entre ibitis e Aegaeas como que materializa a ideia de direcionalidade forjada pela sintaxe-semântica do complemento adverbial do verbo ire (Aegaeas per undas). O verso cesurado confere destaque ao segmento sine me - afinal o eu-lírico terá de abdicar de acompanhar seu general à guerra - de onde aflora a ideia de dor e lamento que se tornará patente no pentâmetro que se segue; fica claro que o $2^{\circ}$ pé que o precede, inteiramente contruído com a gravidade do espondeu realizado pelos dois ditongos-ae-, produz um efeito interjectivo porque evoca a lembrança de um uae! que traduz essa dor, sobretudo quando se pensa na provável diferença de tom com 
que se pronunciam esses ecos de interjeição, produzidos sob efeito do ictus vocálico no início do pé. Interjeições traduzem um efeito emotivo, centrado no eu emissor, portanto, o redobro enfático do pronome em ablativo me, no $4^{\circ}$ pé [cf. me...Me(s), evocativo de memet] parece reforçar tal efeito, de forma a forjar um paralelismo com $A e(\mathrm{~g}) a e-$. A expressão da dor e do lamento quadram bem ao verso heroico e contribuem para o tom grandiloquente que ele procura comunicar. Entretanto, a projeção do recorte dos pés métricos sobre a frase que os realiza relativiza esse tom, porque deixa entrever uma engenhosa e quase despercebida troça: a sílaba -as de Aegaeas forma o $3^{\circ}$ pé com a preposição sine, e, assim, forma também o vocativo asine, que se sintagmatiza com Messalla; ainda que ās-sinnĕ não seja exatamente igual a ăsĭnĕ, sobretudo pela diferença da breve inicial, é inegável que a sugestão existe. Recupera-se, dessa forma, o tema da recusatio, porque sugerir subrepticiamente que Messala é um "asno", um "estulto", introduz o tema tipicamente elegíaco daquele que persegue honras bélicas, em contraste com o eu-elegíaco que as desdenha em nome de uma forma superior de "combate": a militia amoris. Sendo assim, do ponto de vista do discurso elegíaco, quem preferir a guerra a conluios amorosos com a amada só pode ser visto com um olhar depreciativo, ${ }^{13}$ fato corroborado pelo alusivo vocativo ăsinnĕ, semi-oculto pela métrica, mas que pode ser percebido no segmento ās-sĭnĕ do $3^{\circ}$ pé da cadeia prosódica do hexâmetro 1 .

No pentâmetro 1.3.2, o tom queixoso do lamento fica patente pela presença da interjeição $o$ ! em cabeça de verso, destacada pelo ictus e ainda amplificada por um "eco" vocálico em -o-, presente uma vez em memores e duas em cohors. Mas talvez o recurso mais saliente ali seja a cesura fixa pentemímera que, reforçada pela possibilidade de cesura potencial tritemímera, destaca o adjetivo nominativo plural memores ("lembrados" ou "recordandose", "pensando em") e, ao fazê-lo, coloca-o em paralelo com o segmento sine me do verso anterior, produzindo uma espécie de relação causal: porque o eu-poético estará ausente (sine me), ele espera que o general e sua coorte se lembrem dele, retido e adoentado na Feácia; além disso, o 40. pé do hexâmetro (me-Mes-) introjeta o eu-poético no próprio nome de Messala, mercê da constituição do pé métrico por meio de 2 sílabas me, e já parece conter também o germe da expectativa da lembrança veiculada no pentâmetro ( res). Isso sugere uma vez mais a proximidade do eu-poético com seu patrono

\footnotetext{
${ }^{13}$ É corriqueiro dicionários de uso do latim assinalarem várias abonações do sentido figurado de asinus como "tolo, idiota", corrente ao tempo de Tibulo. O OLD (1968), por exemplo, fornece um exemplário que vai de Terêncio e Plauto até Apuleio Madaurense, passando por Cícero, e que contém inclusive o uso do vocativo asine com sentido depreciativo (Cf. OLD, 1968, p. 182, s.v. asinus, 2a. acepção).
} 
Messala (me-Mes- : memores); esse fato é reforçado pelo sândi entre memores e ipse (retomando Messala), sugerindo fusão entre capacidade de memória e a figura do próprio general. O verso encerra-se com mais um pronome que remete à ideia do "eu", sob a forma do complemento em genitivo de memores, ou seja, o pronome mei, que configura a 4a. ocorrência da sílaba -me-, trazendo à cena a ideia do "eu" e materializando sua presença no poema, a fim de construir a lembrança almejada pelo eu-poético. Por fim, o tom algo plangente da esperança de ser lembrado contrasta com a lepidez do ritmo geral do pentâmetro, composto inteiramente de dátilos, ou seja, quatro deles, quando se descontam as duas longas isoladas que caracterizam esse verso.

No hexâmetro 1.3,3 do $2^{\circ}$ dístico, constata-se a $5^{\mathrm{a}} \mathrm{e}$ última ocorrência da sílaba me que encerra a projeção do "eu" no início da elegia co o propósito de realizar a expectativa de o eu-poético ser lembrado. Mais uma vez, o que se afirma no plano do conteúdo está representado de modo semi-simbólico na materialidade da expressão: a Feácia retém, detém e contém o eu-poético adoentado; assim, a cesura pentemímera, auxiliada pela sugestão de uma cesura potencial heftemímera, destaca aegrum ("doente"), que está alocado bem no centro do verso e como que envolvido por Phaeacia e por ignotis, que remete a terris. Outro elemento que atua na mesma direção é o sândi que "funde" tenet + ignotis + aegrum, um recurso que também sugere a contenção do eu-poético enfermo nas terras estranhas e desconhecidas da Feácia. O acúmulo dos fonemas oclusivos /t/, /g/ e /k/ contribui, no contexto, para formar uma certa impressão de dificuldade, já patente no plano de conteúdo do poema. A isso se somam duas novas ocorrências de -ae que, articuladas ao par -ae do 20 pé do hexâmetro inicial, repercute o "eco" da interjeição vae!, ampliando o lamento de dor. Tendo em vista que o hexâmetro do $1^{\circ}$ verso implica a $2^{a}$ pessoa $t u$, por meio da flexão verbal em ibitis, fica clara a oposição ego vs tu tornada concreta pelo me que principia o 20. hexâmetro. Não apenas isso, mas essa oposição é realçada no $1^{\circ}$ pé do hexâmetro 1.3.3 em $\mathbf{M e}$ x te(net); tal recurso torna mais aguda a oposição entre o eu-elegíaco, dedicado à militia amoris, vs. o general Messala, que persegue as glórias da guerra. Pela correspondência entre pé inicial e final desse verso, não é descabido pensar numa ampliação da dicotomia ego $\mathrm{x}$ tu por meio do te contido em terris, que, assim, também recuperaria a natureza da ação de Messala como general, levando a guerra terra marique. Aliás, é preciso notar também que essa sugestão já está prefigurada em outra correspondência, formada pelos pés finais dos dois hexâmetros (1.3,1 e 1.3,3), formados respectivamente por undas (que, mesmo não estando no ablativo, evoca o campo semântico do mar) e terris.

Finalmente, no pentâmetro 1.3,4 do $2^{\circ}$ dístico, a cesura fixa, auxiliada pela sugestão da cesura potencial, destaca Mors, completando, assim, o per- 
curso do cerne dos dísticos iniciais: sine me + memores + aegrum + Mors, o que significa que já não se tem a companhia do eu-elegíaco (sine me), que reclama que seu companheiros lembrem-se dele (memores), gravemente doente (aegrum) e, portanto, ameaçado pela morte (Mors). O paralelismo entre os $1^{\text {os }}$ pés desse pentâmetro e do hexâmetro anterior forja uma quase total paronomásia entre tene(t) e (abs)tine(as). Notável é também a forte presença da vogal -a- (6 vezes), sobretudo no $1^{\circ}$ hemistíquio e recebendo o ictus dos três primeiros pés, e que produz, no contexto, novo eco que remete à interjeição de dor $a$ ! ou $a h$ !. De forma semelhante, o $2^{\circ}$ hemistíquio caracteriza-se pela presença de nasais $/ \mathrm{m} /$ e $/ \mathrm{n} /$ a partir de Mors, no centro do verso. A incidência e repercussão de Mors nigra em modo e manus (pela presença reiterada dos fonemas que os constituem) pode designar tanto o espalhamento da força desagregadora da Morte como o afastamento dessa força, já que ela se concentra somente no $2^{\circ}$ hemistíquio, o que também representa no plano da expressão o afastamento da Morte desejado pelo eu-poético.

Também é preciso notar que os dísticos elegíacos têm um ritmo particular, já que são compostos por um par formado de um verso heroico, o hexâmetro, seguido de um pentâmetro, de que já se disse mais de uma vez que não contém 5 de nada, motivo pelo qual se tem preferido chamá-lo hexâmetro catalético, para evocar de forma mais precisa sua composição, formada de dois primeiros hemistíquios de hexâmetro com cesura pentemímera e colocados em sequência, o que explica melhor a estranha sílaba única no 30 pé, bem como a última sílaba de quantidade indiferente à qual ela estaria associada para formar um hipotético meio-pé descontínuo. Entretanto, a crítica tem desde há muito tempo reconhecido que diferentes tipos de metros podem estar de tal forma associados a diferentes tipos de matéria que veiculam também diferentes sentidos (Fussell 1979, Morgan 2012).

Por essa razão, alguns autores propõem uma leitura estilística do dístico elegíaco, ressaltando o fato de que o hexâmetro é mais afeito à razão própria da matéria heroica, ao passo que o pentâmetro é mais adequado à emoção, de modo que "toute discordance dans cette répartition expressive invite à une interprétation riche d'effects. Mieux encore: la deuxième partie métrico-syllabique du pentamètre est prope à suggérer des effects propements lyriques" (Dangel 2012, 33 n.38). A mesma autora propõe também ler a $2^{\mathrm{a}}$ parte lírica do pentâmetro sem os dois meios-pés central e final, de sorte a realizar uma linha datílico-espondaica nos 3 primeiros pés, finalizando com 2 pés anapésticos, pé a que os gramáticos antigos chamavam um anti-heroico (Dangel, ibid.).

É interessante notar que os artígrafos latinos propuseram várias formas diferentes de escandir versos de assentada tradição como o hexâmetro. Terenciano Mauro, na passagem usada como epígrafe a este texto (q.v.), por 
exemplo, fornece esse mesmo testemunho ao propor que se podem encontrar sequências de versos priapeus em certos hexâmetros virgilianos ${ }^{14} \mathrm{sem}$ que se dê normalmente conta disso, porque, segundo ele, o som ilude os ouvidos: effugit sonus aurem (Terentianus Maurus, De Metris, v. 2771).

Mais que eloquente, esse depoimento é revelador de que há sempre dois níveis de articulação e percepção a serem considerados em análises de expressividade poética, o da realização oral do poema e o de sua leitura, mesmo sabendo que a leitura corresponde, nesse caso, a uma forma de reprodução oral "para si mesmo". Afinal, entre os latinos, a partir de determinada época compunham-se poemas pensando sempre em performances orais, mesmo quando lidos sem o concurso real da voz; por isso, é nessa dimensão do poema em que se situam as questões mais desafiadoras da expressividade. Assim, uma proposta de escansão que atribua finais anapésticos para a metade final do pentâmetro corresponderá a uma mudança significativa no andamento rítmico de cada estrofe, o que sem dúvida leva a novas possibilidades de interpretação da relação entre métrica e expressividade poética do dístico elegíaco.

Provavelmente em razão de sua monotonia excessiva para um emprego em série contínua (кató otíxov), gerada pela estrutura rigorosa do pentâmetro, com sua metade final fixa e separada da metade inicial por uma cesura ou diérese também fixa, mas ambas equivalentes em termos de tempos mínimos ou morae, latinos e gregos sempre o empregaram em associação com o hexâmetro para formar um dístico e, em geral, sempre de modo a encerrar um sentido mais ou menos completo no intervalo formado por esses dois versos (sobretudo no emprego que dele fizeram poetas elegíacos e epigramáticos), o que permite entendê-lo como uma unidade estrófica nos poemas em que ele é empregado (Perini 1982, 226-7). $\mathrm{O}$ andamento rítmico-melódico da unidade estrófica do dístico elegíaco é, por essa razão, muito particular e característico, já que a cesura-diérese fixa do pentâmetro impõe sempre e necessariamente um momento de retomada do andamento do verso. Entretanto, na proposta de escansão que sugere dois pés anapésticos no pentâmetro, como aquela sugerida por Dangel (2012, p. 33, note 38), a sílaba longa que demarcava a cesura-diérese fixa passa a ser a arse que antecede uma tese também longa, formando o terceiro pé espondaico do

\footnotetext{
${ }^{14}$ Como faz notar Cignolo, trata-se ali não de verdadeiros priapeus, mas de hexâmetros com diérese mediana (cf. Cignolo 2002, 564). Seja como for, o testemunho do artígrafo é digno de nota, pois sua interpretação discordante indica, no mínimo, que era percebida uma tensão significativa entre os níveis prosódico e linguístico do verso, um fator a ser explorado em análises de expressividade.
} 
verso. Uma vez adotado o que sugere Dangel, a escansão dos dísticos tomados em análise ficaria como segue:

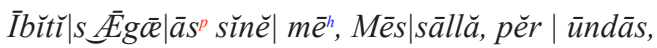

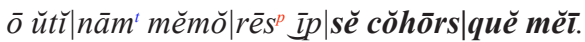

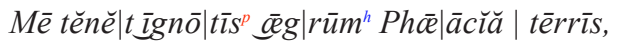

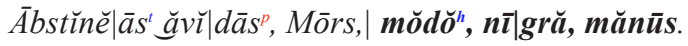

(Tibulo 1.3.1-4)

Ainda que o fenômeno poético pertença à esfera da linguagem verbal, em que não há propriamente música e, sim, musicalidade (sempre em sentido amplo e em contraste o fenômeno musical), é possível tecer certas analogias entre ocorrências poéticas e elementos de música, como o andamento do ritmo musical, de modo a conceber a segunda parte do pentâmetro como uma espécie de contraponto, ou seja, uma espécie de melodia secundária acrescida à principal, ${ }_{15}^{15}$ estabelecida pelo verso heroico. A porção fixa do pentâmetro seria assim uma nova melodia, cujo propósito é propiciar outra direção rítmica ao andamento heroico do hexâmetro, equiparada ou pelo menos identificável à expressão de matéria lírica, sempre conforme sugestão de Dangel (2012, 33 n.38).

O contraponto representado pela parte final do pentâmetro reorienta, por assim dizer, o tom predominantemente marcial da marcha hexamétrica, propondo uma solução inteiramente nova para o andamento heroico. É evidente que uma tal mudança de marcha na leitura / execução do pentâmetro se dá com qualquer uma das duas soluções, seja aquela que o toma como dois pés e meio de hexâmetro, seja a que o entende e executa com dois pés finais anapésticos. Ao contrário da primeira, entretanto, essa última possibilidade estabelece uma interessante tensão rítmica, tendo em vista que anapestos $\left(\cup-\prime^{\prime}\right)$ são o contrário rítmico e temporal exato dos hexâmetros $(-, \cup)$, e que, justamente por isso, eram chamados anti-heroicos pelos

\footnotetext{
${ }^{15} \mathrm{O}$ contraponto é comumente definido como a arte de acrescentar uma ou mais partes a uma dada melodia ou de combinar melodias distintas, de modo a produzir interessantes correlações rítmicas entre essas partes, e divide-se em simples ou duplo (cf. Stainer \& Barrett 2009, 112, s.v. counterpoint). Pode-se estender um pouco mais a analogia e considerar que a segunda metade do pentâmetro funcionaria como uma espécie de contraponto duplo, já que este é definido como uma composição em que as melodias se invertem: o mais alto corresponde ao mais baixo e assim por diante (Stainer \& Barrett 2009, 116). O pé anapéstico (u-, ) é o oposto exato do hexamétrico (-, uu), logo, na proposta de execução de dois anapestos na metade final do pentâmetro, haveria uma conversão do ritmo predominantemente hexamétrico, sempre descendente, para seu correspondente oposto, cujo ritmo é ascendente, o que deve ter funcionado tanto como um índice prosódico, que assinalaria o teor lírico da estrofe, como pontuação para demarcar seu momento de retorno final.
} 
gramáticos antigos, o que também faz deles a parte mais adequada do verso para sugerir efeitos líricos (Dangel, ibid.).

Poder-se-ia dizer finalmente que a tensão criada pela proposta da leitura anapéstica é do tipo tese (andamento heroico) x antítese (andamento lírico), cuja síntese parece ser o próprio dístico, tomado como unidade poemática, o que reforça seu valor estrófico. $\mathrm{O}$ efeito dessa mudança de andamento parece ser o abrandamento do tom grave e solene que a convenção atribuíu à cadência hexamétrica, mais adequada para comunicar feitos de reis e seus generais nas tristes guerras, como assevera conhecida passagem da Ars Poetica (v. 73-4) de Horácio, ${ }^{16}$ e, portanto, inadequada para expressar matéria elegíaca (ou lírica, em sentido amplo).

Nos dois dísticos considerados na análise empreendida neste texto, nota-se que o sentido grave, pesado e solene do andamento do ritmo hexamétrico seria interrompido no instante em que atingiria o ápice: a partir do terceiro pé do pentâmetro, ainda heroico e mais grave e solene que os demais, porque realizado por um pé espondaico, o tom passa de grave a leve com o arremate de dois anapestos finais, de modo a fornecer um contraponto

${ }^{16}$ Res gestae regumque ducumque et tristia bella / quo scribi possent numero, monstrauit Homerus. / Versibus impariter iunctis querimonia primum, (75) / post etiam inclusa est uoti sententia compos; I quis tamen exiguos elegos emiserit auctor, / grammatici certant et adhuc sub iudice lis est. (Hor., A.P., v. 73-8). Na tradução francesa de Villeneuve, "En quel rythme on pouvait écrire les hauts faits des rois, ceux des chefs, et les sombres guerres, Homère l'a montré. Dans l'union de deux vers inégaux on enferma d'abord la plainte, puis la satisfation d'un voeu exaucé. Quel créateur pourtant inventa la brièveté des vers élégiaques? Les grammairiens en disputent et le process est encore pendant" (Villeneuve, in: Horace 1989, 206) ou, em decassílabos portugueses, "Feitos de reis, dos chefes, tristes guerras / em que verso escrever mostrou Homero. / Em versos não parelhos, o lamento / antes, e o voto obtido após incluiu-se. / Das breves elegias o criador / quem seria debatem os gramáticos / mas inda está sub júdice o litígio. Horácio evoca nessa passagem a autoridade inquestionável de Homero para abonar a adequação do emprego do hexâmetro para a expressão da matéria épica, bem como do dístico elegíaco (uersibus impariter iunctis) para comunicar seus temas mais antigos, quais sejam o lamento fúnebre (quaerimonia) e os epigramas votivos (uoti sententia compos), muito embora o dístico tenha evoluído até transformar-se, em Roma, no principal verso estrófico da matéria amorosa (Horacio 2008, 388 n.100). É interessante notar que a alusão ao dístico elegíaco é feita por uersibus impariter iunctis, e que parece ser o único registro de uso do advérbio impariter ("impariter is apparently a coinage of H.'s": Horace 1989, 163 n.75. Cf.: esse verso é também a única abonação de impariter fornecida pelo OLD, 1968). Parece, portanto, fora de dúvida que uma atenção especial recai sobre seu sentido no sintagma. No OLD (p. 1297), o $2^{\circ}$ sentido do advérbio pariter assinala "em igual quantidade, medida ou grau; da mesma forma, tanto quanto; de modo nivelado, uniforme", logo, impariter corresponde à negação, isto é, ao contrário de todos esses sentidos. Sempre se vê em uersibus impariter iunctis uma alusão à óbvia diferença entre os versos hexâmetro e pentâmetro, uma interpretação consagrada por todas as traduções da Ars Poética em línguas modernas, como por exemplo a de Villeneuve citado aqui, que faz corresponder ao adv. um adjetivo para a palavra verso ("deux vers inégaux"); mas também é possível entender que Horácio tenha talvez explorado a polissemia de seu neológico impariter, de modo a indicar também a união desnivelada e não uniforme dos versos, embora de forma não a indicar apenas a mera diferença entre seus número de pés (6 no hexâmetro e 5 no pentâmetro), mas também e sobretudo a mudança de andamento rítmico imposta pela segunda parte do pentâmetro, que deixaria o conjunto intencionalmente desnivelado e desequilibrado, sentido também indicado por impariter. 
ao sentido sério e grave de cada dístico: no primeiro deles, a empreitada marítima de Messala (tema por excelência épico), pontuada pela ausência do eu-elegíaco, é interrompida pelo ritmo ascendente e "saltitante" dos anapestos finais, formados pela sequência -se cohorsque mei; da mesma maneira, no segundo, a gravidade da doença e a possibilidade da chegada iminente da negra Morte, marcadas solenemente pelo ritmo hexamétrico, são abrandadas pelo mesmo expediente anapéstico da sequência modo, nigra, manus, cujo contraste com a porção precedente parece sugerir até mesmo certa dose de zombaria em relação aos mais traços lúgubres da figura da Morte.

Finalmente, é preciso lembrar que tais efeitos também correspondem, ao menos em parte, a certos aspectos programáticos da produção elegíaca em Roma, como, por exemplo, certos efeitos de humor que poderiam resultar do contraste anapéstico há pouco discutido. Dessa forma, é possível pensar em que as influências e antecedentes históricos da elegia latina alicerçados na Comédia Nova e seus desdobramentos plautinos podiam ter raízes mais recuadas e profundas do que se imagina, como, aliás, a crítica moderna começa a perceber (cf., por exemplo, James 2012, 253-68). A instigante sugestão do contraponto anapéstico do final do pentâmetro pode, talvez, representar mais um passo nessa mesma direção. Como quer que seja, a possibilidade de entrever outras formas de interpretação rítmica do pentâmetro já fornece novas e interessantes direções para as análises da expressividade desse verso e do dístico elegíaco do qual ele faz parte.

\section{REFERÊNCIAS}

Brunet, Philippe. 2010. "Préface" à l'Iliade, d'Homère, 7-39. Paris: Seuil.

Bright, D. F. 1971. "A tibullan odyssey." Arethusa 4:197-214.

Campbell, C. 1973. "Tibullus: elegy I.3." Yale Classical Studies 23:147-53.

Casanova-Robin, Hélène, ed. 2007. Amor scribendi: lectures des Hérö̈des d'Ovide. Grenoble: Jérôme Millon. (Collection Horos).

Catullus, Gaius Valerius. 2005. The poems of Catullus. Translated with commentary by Peter Green. Berkely, Los Angeles (CA-USA) / London (UK): University of California Press.

Chantraine, Pierre. 1968-1980. Dictionnaire étymologique de la langue grecque. Histoire des mots. 5 tomes et $4 \mathrm{v}$. Paris: Klincsieck.

Cignolo, Chiara. 2002. "Commento" a De litteris, de syllabis, de metris, di Terentianus Maurus. Vol. 2: Commento, appendici e indici. Ed. Chiara Cignolo. Hildesheim / Zürich / New York: Georg Olms Verlag.

Daitz, Stephen G. 1984. The pronunciation and reading of classical Latin: a practical guide. Guilford (USA-CT) / London (UK): Jeffrey Norton Publishers. 
Dangel, Jacqueline. 2007. “Intertextualité et intergénéricité dans les Héroïdes d'Ovide: la métrique à l'oeuvre." In Amor scribendi: lectures des Hérö̈des d'Ovide, éditée par Hélène Casanova-Robin, 13-35. Grenoble: Jérôme Millon.

Ernout, Alfred; Meillet, Alfred. 2001. Dictionnaire étymologique de la langue latine. Histoire des mots. 4e édition augmentée d'additions et des corrections de Jacques Andrés. Paris: Klincsieck.

Glare, P. G. W. et al., ed. 1968. Oxford Latin Dictionary (OLD). Oxford (UK): Oxford University Press.

Gold, Barbara K., ed. 2012. A Companion to Roman Love Elegy. Malden (USA-MA) / Oxford (UK) / Chichester (UK): Wiley-Blackwell.

Homer. 1945. The Odyssey (vol. 1). With an English transl. by A. T. Murray. Cambridge (MA-USA) / London (UK): William Heinemann. (The Loeb Classicla Library).

Horace. 1989. Epistles - Book II and Epistle to the Pisones ('Ars Poetica'). Ed. by Niall Rudd. Cambridge (UK): Cambridge University Press.

Horace. 1989. Épitres. Texte établi et traduit par François Villeneuve. 8e. ed. Paris: Belles Lettres.

Horacio. 2008. Sátiras. Epístolas. Arte Poética. Introducciones, traducción y notas de José Luis Moralejo. Madrid: Gredos.

Jakobson, Roman. 1962. Selected writings, I: Phonological studies. The Hague: Mouton.

James, Sharon L. 2012. "Elegy and New Comedy." In A Companion to Roman Love Elegy, edited by Barbara K. Gold, 253-68. Malden (MA-USA) / Oxford (UK): Wiley-Blackwell.

Livy. 1957. History of Rome (vol. 1: Books I and II). With an English transl. by B. O. Foster. Cambridge (MA-USA) / London (UK): William Heinemann. (The Loeb Classicla Library).

Mills, D. H. 1974. "Tibullus and Phaeacia: a reinterpretation of I,3." Classical Journal 69:226-33.

Morgan, Llewelyn. 2012. "Elegiac Meter: Opposites Attract." In A Companion to Roman Love Elegy, edited by Barbara K. Gold, 204-18. Malden (MA-USA) / Oxford (UK): Wiley-Blackwell.

Perini, Giorgio Bernardi. 1982. "Fondamenti di metrica." In Propedeutica al latino universitario, di A. Traina \& G. B. Perini, 201-41. Bologna: Pàtron.

Saussure, Ferdinand de. 1995. Cours de linguistique générale. Publié par Charles Bailly et Albert Séchehaye avec la collaboration de Albert Riedlinger. Paris: Payot \& Rivage.

Stainer, John; Barrett, William. 2009. Dictionary of musical terms. New York (USA): Cambridge University Press.

Terentianus Maurus. 2002. De litteris, de syllabis, de metris. Vol. 1: Introduzione, testo critico e traduzione italiana. Vol. 2: Commento, appendici e indici. Ed. Chiara Cignolo. Hildesheim / Zürich / New York: Georg Olms Verlag. (Bibliotheca Weidmanniana 6: Collectanea Grammatica Latina 2.1, 2.2).

Terentianus Maurus. 1923. Terentiani Mauri De litteris, de syllabis, de metris libri tres. In Grammatici latini, hrsg. Heinrich Keil, vol. VI. Lipsiae.

Tibulle. 1950. Tibulle et les auteurs du Corpus Tibullianum. Texte établi et traduit par M. Ponchont. Paris, Belles Lettres. 
Title. Rhythm and expressiveness of the elegiac couple: Tibullus 1.3.1-4.

Abstract. From the recognition that long and short syllables mutually (cor)respond in a system of basic oppositions, it is essential to verify which role is played by them in the phonosyntactic chains that form metric feet, a function that they only perform through psychological values invested in the hierarchically organized structures of the verse, which are generated from the basic opposition they have started. Such values are the combinatorial properties permited by the next level segments in a phonological chain, which are the poetic meters followed by the metric feet that they perform or integrate, then the verse itself and eventually the whole stanza, so as to provide structure to the whole poem. Since this process always consists of a concatenation of elements, the set thus formed tends to generate orientation, that is, meaning, which is, in principle, a certain poetic rhythm. The rhythm, however, is influenced by other occurrences along the phonosyntactic chain, such as the caesuras that affect the line of a verse. From the passage of Tibullus, 1.3.1-4, the present text aims to take into account such factors to analyze the rhythmic-melodic pace of the strophic unit formed by the elegiac couple, with special focus on the possibilities of scansion generated by the fixed caesura-diaeresis of the so-called pentameter and their consequences for poetic expressiveness.

Keywords. Poetic rhythm; Elegiac couple; scansion; Tibullus; Semiology; expressiveness. 